\title{
Characterization and Differentiation of Heterocyclic Isomers. Tandem Mass Spectrometry and Molecular Orbital Calculations on 3-Methylisoxazolo- and 2-Methyloxazolopyridines*
}

\author{
Gianluca Giorgi \\ Centro Interdipartimentake di Analioj e Determinazioni Strutturali, L niversità di Siena, via P. A. Mattioli, \\ $10-53100$ Siena, Itals
}

\author{
Fabio Ponticelli \\ Istituto di Chimica Organiea, Lniverstì di Siend, Pian dei Mantellini, 44 - 53100 Siena, Italy \\ Gábor Czira and Károly Vékey \\ Central Research Institute for (hemistrs: Ilumgarian Academs of Sciences, Pustasceri ut 59-67 - 1025 \\ Budapest, Hungary
}

\begin{abstract}
Metastable mass-analyzed ion kinetic energy (MIKE) and collision-induced dissociation MIKE spectrometries have been applied to the study of all members of two classes of heteroaromatic isomers: 3-methylisoxazolo- and 2-methyloxazolopyridines. The study revealed that tandem mass spectrometry can characterize and differentiate the isomeric ion structures produced by these heterocycles. In particular, the MIKE spectra of both the molecular ions and abundant fragments formed by $\mathrm{CO}$ and $\mathrm{CH}_{3} \mathrm{CN}$ losses show characteristic differences that allow distinction among the isomers dependent on the position of the nitrogen atom in the pyridine ring, and distinction of isoxazole derivatives from oxazoles. The results indicate that the isomerization of the isoxazole moiety to oxazole-proposed for other analogous compounds-does not occur in these heterocyclic systems. The experimental work is supported by molecular orbital calculations both on neutral molecules and on molecular and fragment ions. (] Am Soc Mass Spectrom 1995, 6, 962-971)
\end{abstract}

I dentification and structural characterization of isomeric compounds are very important problems in various branches of chemistry. Among other analyt ical techniques, mass spectrometry is a very powerful tool for an unambiguous identification and assignment of the structure of a compound. Unfortunately, isomers often follow the same fragmentation pathways in the source region and produce nearly identical mass spectra that do not allow distinction of one compound from the others. It follows that more specific techniques are required [1].

Metastable decomposition processes can be a valid probe for the differentiation of isomeric ion structures.

Address reprint requests to Dr. Cianluca cibrgi. Centro lnterdiparti. mentale di Analisi e Determinacioni Strutturali, Lniversita di Siena, via P. A. Mattioli, 10, 53100 Sit'na. Italy.

"Dedicated to Protessor Cr. Adembri on the accaston of his fith birthday:
On the other hand, the high similarity in metastable processes of ions that originate from different neutral molecules often indicates the same reacting configuration. In this case isomerization phenomena, which consist either of the interconversion from one isomer to another or of the isomerization to a common structure, occur in the gas phase [2].

Mass spectrometry has been applied widely to the characterization of heteroaromatic compounds that contain nitrogen and oxygen atoms [3]. In particular, fused ring systems that contain the isoxazole or the oxazole moiety have been the subject of several papers [4-12]. On the basis of the electron ionization spectra, a previous study carried out on 1,2-benzisoxazole $N$ oxides [7] proposed that the impact-induced isomerization of the radical ion produced by initial deoxygenation of $\mathrm{M}^{+\cdot}$ gave a structure that corresponds to the oxazole isomer. The photochemically induced isomerization of 3,5-diphenylisoxazole to 2,5-diphenyl- 
oxazole via an azirine intermectiate also was reported [13]. This behavior was similar to that found under electron ionization conditions [14]. Isomerization of the molecular ion of benzoxazole to $\alpha$-cyanophenol precedes its fragmentation under electron ionization [15]. For 2,1-benzisoxazole, which presents a different $\mathrm{fu}^{-}$ sion of the two rings, the opening of the five-membered ring has been proposed to yicld an ion with a common structure to that produced by rearrangements of isatin and anthranilic acid [15]. The study of the ion kinetic energy spectra of analogous heterocyclic isomers 1,2-benzisothjazole and benzothiazole revealed a common structure of the inolecular ions, which indicates that the isomerization of the isothiazole moiety to a thiazole derivative occurs under electron ionization conditions [16].

Our interest here is focused on the characterization and differentiation of 3-methylisoxazolo- $(\mathbf{1 a}-\mathbf{d})$ and 2-methyloxazolopyridine $(\mathbf{2 a} \cdot \mathbf{d})$ isomers (Scheme I), for which the electron ionization (EI) spectra have been published recently [17]. From those data, although it is possible to differentiate isomers $1 \mathbf{a}$ and $2 \mathbf{a}$ from the others, it is very difficult to distinguish among corresponding compounds that belong to the series 1 and 2 . This is due to the fact that the same fragmentation pattern, which consists mainly of a competitive loss of $\mathrm{CO}$ and $\mathrm{CH}_{3} \mathrm{CN}$ from the molecular ion, occurs in the source region for all of these compounds.

To gain information on the structure of the molecular and fragment ions that originate from isoxazole $(\mathbf{1} \mathbf{a}-\mathbf{d})$ and oxazole $(\mathbf{2} \mathbf{a}-\mathbf{d})$ derivatives under electron ionization conditions, we carried out a tandem mass spectrometry investigation on these compounds as well as on the trideuteromethyl derivative of $1 \mathrm{~d}$ (1e). It is particularly interesting to ascertain whether isomerization of the isoxazole moiety to oxazole, proposed for analogous heterocycles, occurs in these molecules.

The experimental work is supported by theoretical calculations. Theoretical approaches may be employed usefully to study the properties of gas-phase ions [18]. In particular, molecular orbital theory has been shown

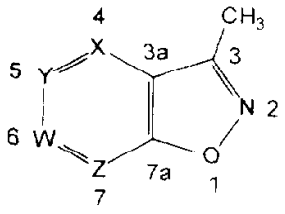

1

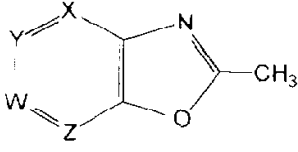

2

$$
\begin{array}{lll}
\text { a. } & X=N & Y=W=Z=C H \\
\text { b. } & Y=N & X=W=Z=C H \\
\text { c. } & W=N \quad X=Y=Z=C H \\
\text { d. } & Z=N \quad X=Y=W=C H \\
& \text { Scheme I. }
\end{array}
$$

to be a useful tool to support mass spectrometric investigations in the interpretation and prediction of primary fragmentation processes [19].

Beyond classical parameters (heats of formation and Mulliken's overlap bond orders), other inherent parameters, such as bond orders, diatomic energy contributions, and valences (or free valences for open-shell systems), have been used successfully to study several classes of molecules that range from organic, heterocyclic, and organometallic compounds to peptides. (For a detailed background and a comprehensive literature review on this field, see ref 20 and references therein). In this work molecular orbital calculations based on the modified neglect of differential overlap (MNDO) method [21] have been carried out on neutral $\mathbf{1 a}-\mathbf{d}$ as well as on their molecular and $\left[\mathrm{M}-\mathrm{CH}_{3} \mathrm{CN}\right]^{+\cdot}$ fragment ions.

\section{Experimental}

\section{Mass Spectrometry}

Compounds $1 \mathbf{a}-\mathbf{e}$ and $\mathbf{2 a}-\mathbf{d}$ were synthesized and purified as previously reported $[17,22,23]$. Mass spectrometric measurements were performed on a VG ZAB-2SEQ hybrid tandem mass spectrometer (VG Analytical Ltd., Manchester, UK) with configuration $B E q Q$ coupled to an OPUS 2000 data system. Electron ionization was performed at $70 \mathrm{eV}$ with a source temperature of $140{ }^{\circ} \mathrm{C}$. The accelerating voltage was $8 \mathrm{kV}$ and the resolution was $1000 \mathrm{M} / \Delta M$ (10\% valley). High energy collision-induced dissociation (CID)-MIKE experiments were carried out by introduction of helium into the collision cell situated in the second field free region (FFR) to produce a reduction of the main beam intensity to $50 \%$. To increase the resolution of daughter ions in the mass-analyzed ion kinetic encrgy (MIKE) experiments, E/Q linked scans were performed at unit resolution of the quadrupole analyzer. Replicated measurements showed that the reproducibility of the relative peak abundances in MIKE and CID-MIKE spectra was within $10 \%$.

\section{Theoretical Calculations}

Semiempirical molecular orbital calculations were performed on compounds $1 \mathbf{a}-\mathbf{d}$, both on neutral species and on molecular and $\left[\mathrm{M}-\mathrm{CI}_{3} \mathrm{CN}\right]^{+}$fragment ions. All calculations were carried out by using the program MOPAC version 4.0 [24] implemented on a Digital VAX 6610 computer (Digital Equipment Corp., Maynard, $(A)$ and the method MNDO [21]. The molecular geometry was fully optimized without any constraints. The restricted Hartree-Fock and unrestricted Hartree-Fock formalisms were used for calculations on closed-shell and open-shell $\mathbf{1 a}-\mathbf{d}$ species, respectively. In the case of fragment ions, because severe spin contamination was observed in most of the cases, the half-electron method was used. 


\section{Results and Discussion}

\section{Tandem Mass Spectrometry}

Molecular ion. MIKE spectral data of the molecular ion from isoxazole $(\mathbf{1} \mathbf{a}-\mathbf{d})$ and oxazole $(\mathbf{2} \mathbf{a}-\mathbf{d})$ isomers are reported in Table 1 . A comparison between the spectra of $\mathbf{1 a}, \mathbf{d}$ and their oxazole isomers $\mathbf{2 a}, \mathbf{d}$ is depicted in Figure 1.

For all the four isomers 1 the main metastable processes are the losses of $\mathrm{H}^{\cdot}$ and $\mathrm{CO}$. The first process is highly favored for isomer $1 \mathbf{1}$, whereas for the others the loss of $\mathrm{CO}$ is the most abundant. The latter is a flat or slightly dish-topped peak with a kinetic energy release, measured at half height $\left(T_{0}\right)$, equal to $630 \mathrm{meV}$ for compounds $1 \mathbf{a}-\mathbf{c}$, and $420 \mathrm{meV}$ for 1d (insets in Figure 1 top row), which indicates a high reverse activation energy [2]. This is in agreement with rearrangements that have to occur in the molecular ion that involve the opening of the two ring systems to allow the elimination of $\mathrm{CO}$.

For compounds $1 \mathrm{a}$ and $1 \mathrm{c}$ other peaks are at $m / z 93$ and 79. These simple-Gaussian type metastable peaks [25] correspond to the losses of $\mathrm{CH}_{3} \mathrm{CN}$ and $\mathrm{C}_{2} \mathrm{HNO}$, respectively, from the molecular ion. The $T_{05}$ values associated with the first process are $17 \mathrm{meV}$ for both isomers - much lower than those relevant to the loss of $\mathrm{CO}$. 1d does not show loss of $\mathrm{CH}_{3} \mathrm{CN}$, but only of $\mathrm{C}_{2} \mathrm{HNO}$

The MIKE spectrum of the 3-trideuteromethyl derivative of $1 \mathbf{d}, 1 \mathbf{e}(\mathrm{m} / z \mathrm{137})$ shows peaks at $m / z 136$ and 135 , with a relative intensity ratio equal to $\sim 1: 10$. This indicates the prevailing loss of one deuterium radical from the methyl group with very little scrambling of the deuterium atoms. Other metastable peaks are at $m / z 109$, which correspond to the loss of $\mathrm{CO}$, and at $m / z 81$, two atomic mass units higher than in the spectrum of $1 \mathbf{d}$, which indicates that in this fragmentation one deuterium atom is lost.

From these results it follows that the molecular ions of the four isoxazole isomers $1 \mathbf{a}-\mathbf{d}$ produce different MIKE spectra, which allow an unambiguous identification of each compound. It is noteworthy that there are large differences between the EI [17] and the MIKE spectra of compound 1a. Although the loss of $\mathrm{CH}_{3} \mathrm{CN}$ is highly favored compared with loss of $\mathrm{CO}$ in the source, in metastable processes the two pathways are of comparable abundance.

The MIKE spectra of the molecular ions from the oxazole derivatives $\mathbf{2 a}-\mathbf{d}$ (Table 1 and Figure 1) are significantly different from those produced by the isoxazoles $1 \mathbf{a}-\mathbf{d}$. The most remarkable difference consists

Table 1. MIKE and CID-MIKE (numbers in italics) data (relative intensity, $\%)$ of $\mathrm{M}^{+*}(m / 2134)$ produced from isomers 1 and 2

\begin{tabular}{|c|c|c|c|c|c|c|c|c|}
\hline Ion & $1 \mathrm{a}$ & $2 a$ & $1 \mathrm{~b}$ & $2 b$ & $1 \mathrm{c}$ & $2 c$ & $1 d$ & $2 d$ \\
\hline \multirow[t]{2}{*}{133} & 100 & 100 & 25.0 & 58.9 & 28.0 & 44.8 & 28.9 & 100 \\
\hline & 29.3 & 87.6 & 45.9 & 100 & 56.1 & 100 & 47.6 & 100 \\
\hline 119 & 2.1 & & 3.8 & 3.3 & & 2.0 & 4.8 & \\
\hline \multirow[t]{2}{*}{107} & & 9.2 & & & & & & 3.4 \\
\hline & & 5.0 & & & & & & 21.2 \\
\hline \multirow[t]{2}{*}{106} & 39.7 & & 100 & 100 & 100 & 100 & 100 & \\
\hline & 20.3 & & 100 & 83.6 & 100 & 31.2 & 100 & \\
\hline \multirow[t]{2}{*}{105} & & 4.9 & & & & & & 8.5 \\
\hline & & 11.0 & & & & & & 30.5 \\
\hline \multirow[t]{2}{*}{104} & 6.0 & 3.9 & & 34.2 & & & & 5.4 \\
\hline & 3.1 & & & 21.0 & & & & 13.6 \\
\hline 103 & & & 2.5 & 5.5 & & 5.0 & & \\
\hline \multirow[t]{2}{*}{94} & & & & 6.2 & & & & \\
\hline & & & & 44.1 & & & & \\
\hline \multirow[t]{2}{*}{93} & 40.7 & 30.6 & & 27.4 & 41.1 & 86.7 & & \\
\hline & 100 & 100 & 9.3 & 30.7 & 67.0 & 72.5 & 3.0 & \\
\hline \multirow[t]{2}{*}{92} & & & & 92.0 & & & & \\
\hline & & & 3.2 & 44.3 & & & & 2.7 \\
\hline 91 & & & & & & 4.0 & & 1.5 \\
\hline \multirow[t]{2}{*}{81} & & & & 16.4 & & & & \\
\hline & & & & 52.4 & & & & \\
\hline \multirow[t]{2}{*}{79} & 2.8 & 2.9 & & 35.0 & 5.7 & 8.4 & 4.9 & 2.3 \\
\hline & & 2.0 & 8.2 & 28.3 & 12.2 & 6.2 & 6.2 & 5.4 \\
\hline 65 & 8.4 & 10.3 & & 17.4 & 9.8 & 10.3 & & 2.2 \\
\hline 64 & 5.6 & 6.6 & 5.3 & 13.4 & 9.8 & & 3.0 & 2.2 \\
\hline 38 & 2.0 & 2.6 & 3.3 & & 4.8 & 5.9 & & \\
\hline
\end{tabular}


of the presence of a multiple peak in the region of $\mathrm{m} / \mathrm{z}$ 104-107 in the MIKE spectra of compounds $2 \mathbf{a}$ and $2 \mathrm{~d}$. It has been resolved by means of $E / Q$ linked scans (insets in Figure 1 bottom row) in which, through use of the unit resolution of the quadrupole analyzer, a better separation of the daughter ions can be achieved. This has allowed the multiple peak to be assigned to three components at $m / 2104,105$, and 107. Although the first two peaks correspond to the losses of $\mathrm{CH}_{2} \mathrm{O}$ and $\mathrm{CHO}^{\circ}$, respectively, the third peak, which is 27 mass units lower than the molecular ion, reasonably can be attributed to the loss of HCN. In the EI spectra, this peak has a very low intensity and it previously has been attributed to the isotopic contribution of the ion at $m / z 106$ [17]. Comparison of MIKE and $E / Q$ MIKE spectra suggests that there are some differences in relative intensity ratios measured by the two techniques (Figure 1). These differences may be due partly to the overlapping of peaks with different widths in the MIKE spectra and partly to distorsions due to the quadrupole tuning in the $E / Q$ scans.
In the region of $m / z$ 104-107, the MIKE spectra from $2 \mathbf{b}$ and $\mathbf{2 c}$ show a flat-topped metastable peak at $m / z 106$ due to the loss of $\mathrm{CO}$ with $T_{0.5}$ values equal to 480 and $600 \mathrm{meV}$, respectively. For $2 \mathrm{~b}$ the loss of $\mathrm{CH}_{2} \mathrm{O}$ also is observed. In the region $\mathrm{m} / \mathrm{z} 90-70$, the behavior of $\mathbf{2 a}, \mathbf{2 c}$, and $\mathbf{2 d}$ reflects that of the corresponding isoxazole derivatives that yield metastable peaks at the same mass-to-charge ratio values but with some difference in their relative intensity.

It is interesting to note the different behavior of $\mathbf{2 b}$ in comparison with $\mathbf{1 b}$. Both compounds show the losses of a hydrogen radical and $\mathrm{CO}$, but although they are the only metastable processes for $\mathbf{1 b}, \mathbf{2} \mathbf{b}$ further produces metastable peaks at $m / z 104,93,92,81$, and 79 (Table 1). In particular, the peaks at $\mathrm{m} / z 92(92.0 \%)$ and $81(16.4 \%)$, attributable to the losses of $\mathrm{CH}_{2} \mathrm{CO}$. and $\mathrm{C}_{2} \mathrm{HN}_{2}{ }^{\circ}$, differentiate $2 \mathrm{~b}$ from the other isomers.

High energy CID-MIKE spectra of the molecular ion from all isoxazole and oxazole derivatives (Table 1) provide further evidence that the reacting ion structures for isomers $\mathbf{1} \mathbf{a}-\mathbf{d}$ and $\mathbf{2 a}-\mathbf{d}$ are different, which
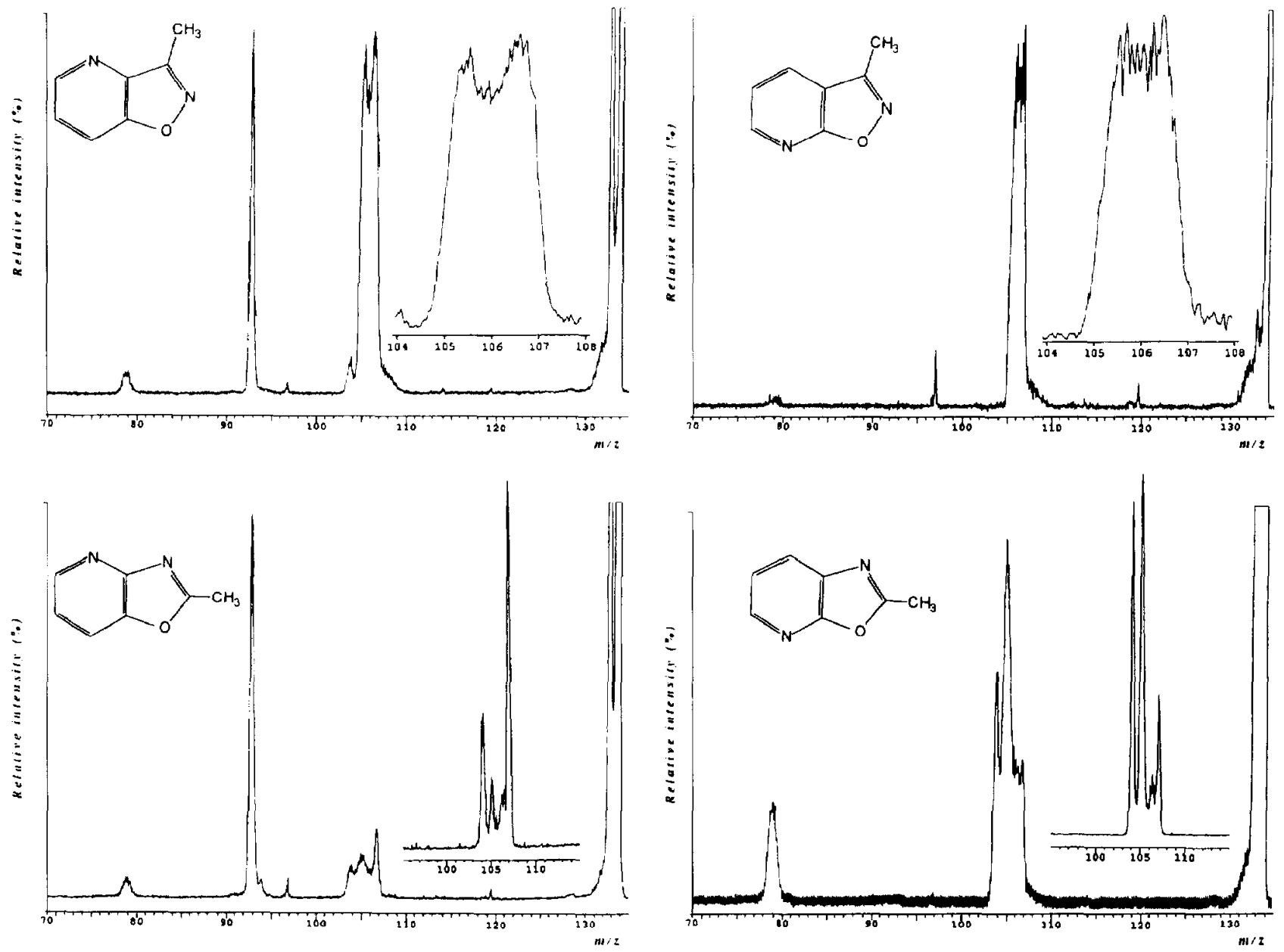

Figure 1. Comparison between MIKE spectra of $\mathrm{M}^{+*}(\mathrm{~m} / \mathrm{z} 134)$ from isoxazoles $1 \mathbf{a}$ and $1 \mathbf{d}$ (top row) and their corresponding oxazoles $2 a$ and $2 d$ (bottom row). For the latter, a portion of the $E / Q$ scan is shown in the insets. 
indicates that the isoxazole $\rightarrow$ oxazole comversion also does not occur in these experimental conditions. Beyond the processes already observed in MIKE spectra, an interesting feature is the loss of the methyl group from isomers $\mathbf{1 a}, \mathbf{1 b}, \mathbf{1 d}$, and $\mathbf{2 c}$. Furthermore, peaks at $m / z 65,64$, and 38 that correspond to losses of $\mathrm{C}_{3} \mathrm{H}_{3} \mathrm{NO}, \mathrm{C}_{3} \mathrm{H}_{4} \mathrm{NO}$, and $\mathrm{C}_{4} \mathrm{H}_{4} \mathrm{~N}_{2} \mathrm{O}$, respectively, are present. As an example, the CID-MIKE spectra of $1 \mathrm{c}$ and $2 \mathrm{c}$ are shown in Figure 2.

IM $-\mathrm{COI}^{+}$fragment ion. The MIKE spectra of the $[\mathrm{M}-\mathrm{CO}]^{+\cdot}$ ions $(\mathrm{m} / \mathrm{z} 106)$ formed in the source also were studied. The data are summarized in Table 2. All
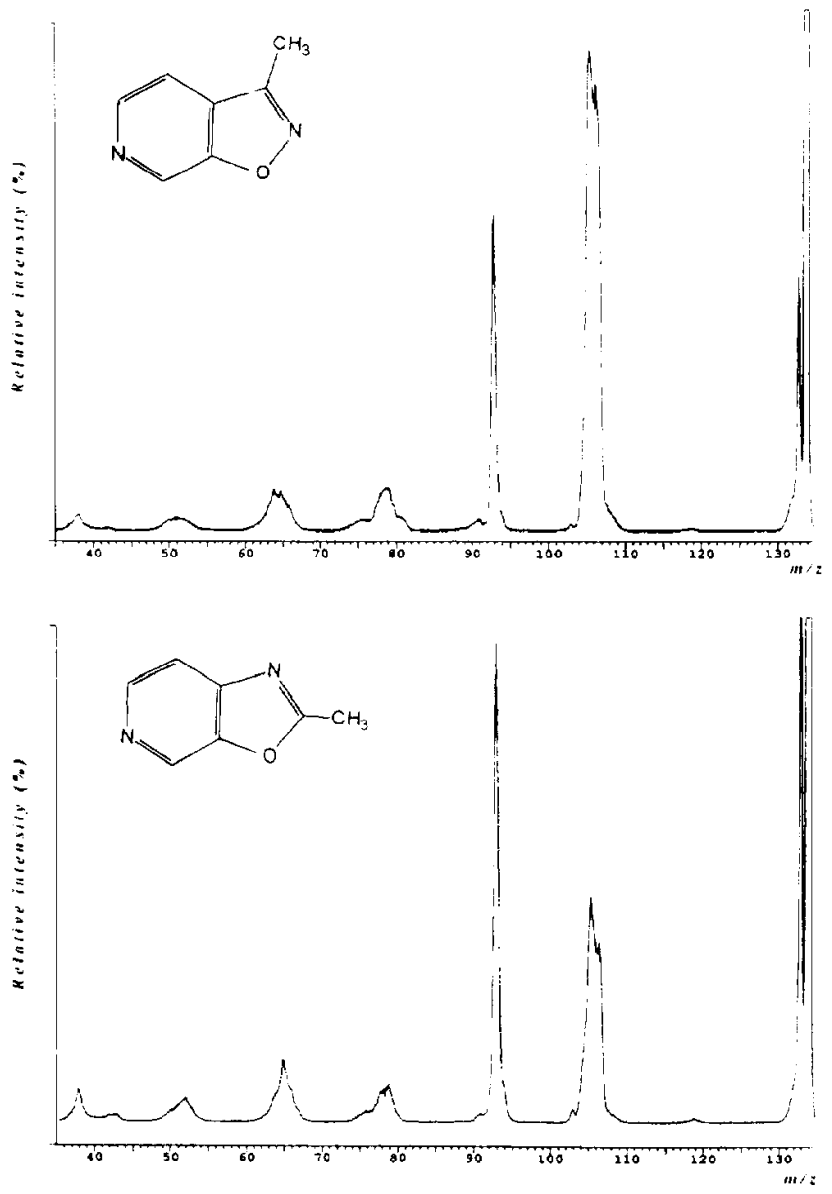

Figure 2. CID-MIKE spectra of $\mathrm{M}^{\cdots}(\mathrm{m} / \mathrm{z} / \mathrm{134})$ from compounds $1 \mathrm{c}$ (top) and $2 \mathrm{c}$ (bottom). the metastable processes observed for $[\mathrm{M}-\mathrm{CO}]^{+}$. fragments ions are due to simple-Gaussian type peaks [25] with $T_{0.5}$ values in the range 20 to $100 \mathrm{meV}$. As an example, a comparison between the metastable spectra of the isoxazole 1a and oxazole 2a is shown in Figure 3. The isomers $1 \mathbf{a}-\mathbf{d}$ show a preeminent loss of a hydrogen radical as well as other metastable peaks at $m / z$ 79,66 , and 55 that can be attributed to the losses of $\mathrm{HCN}, \mathrm{C}_{2} \mathrm{H}_{2} \mathrm{~N} \cdot$, and $\mathrm{C}_{3} \mathrm{HN}$, respectively. In the spectra of $1 b$ and $1 c$ a further metastable fragmentation pattern is evidenced by a peak at $m / z 65$ due to the loss of $\mathrm{CH}_{3} \mathrm{CN}$.

A comparison between the spectra of isomers $\mathbf{1} \mathbf{a}-\mathbf{d}$ and $\mathbf{2} \mathbf{a}-\mathbf{d}$ shows remarkable differences. In
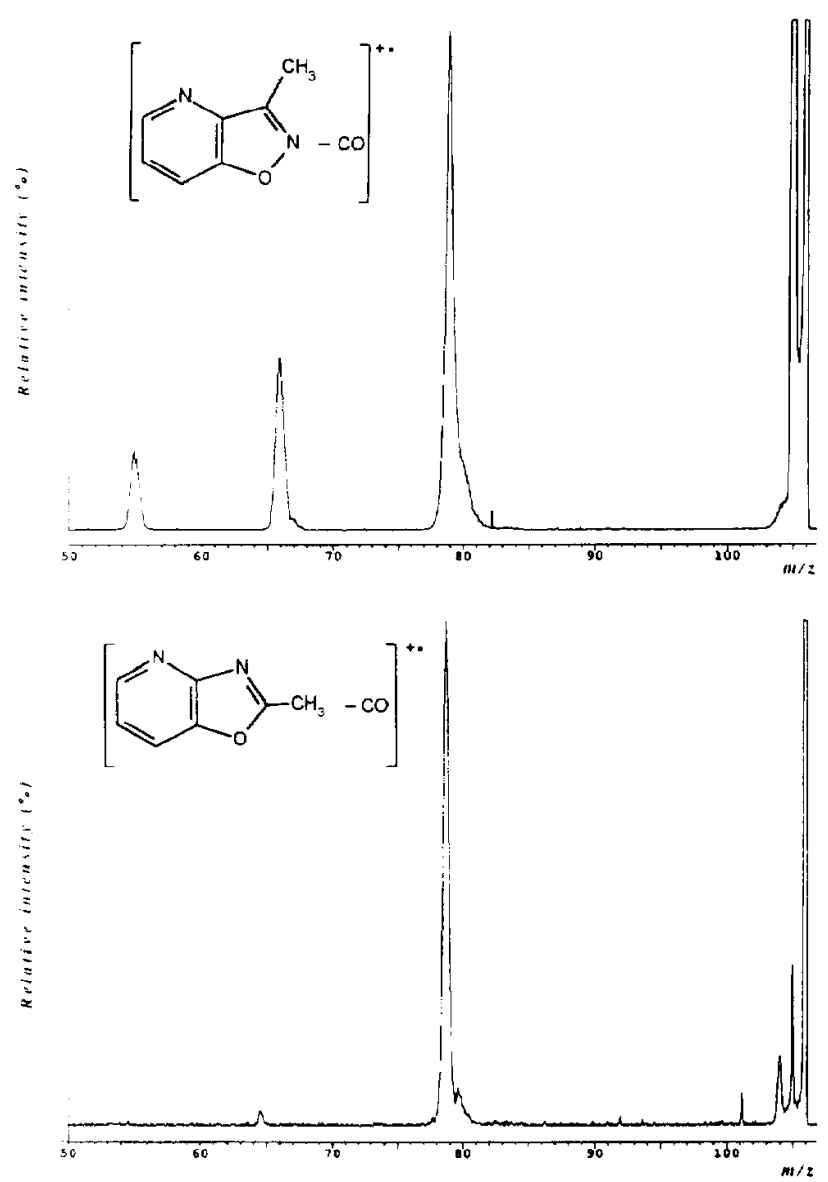

Figure 3. Comparison of MIKE spectra of the $[\mathrm{M}-\mathrm{CO}]^{+\cdot}$ ion $(\mathrm{m} / \mathrm{z} 106)$ from isomers $\mathbf{1 a}$ (top) and 2a (bottom).

Table 2. MIKE data (relative intensity, $\%)$ of $[\mathrm{M}-\mathrm{CO}]^{\cdots}(\mathrm{m} / \mathrm{z} 106)$ produced from isomers 1 and 2

\begin{tabular}{lcccccccr}
\hline Ion & 1a & 2a & 1b & 2b & 1c & 2c & 1d & 2d \\
\hline \hline 105 & 100 & 33.1 & 100 & 100 & 100 & 100 & 100 & 100 \\
80 & & 10.5 & & 21.5 & & 27.2 & & 1.8 \\
79 & 73.8 & 100 & 83.2 & 88.1 & 68.7 & 80.8 & 83.2 & 83.2 \\
66 & 27.7 & & 45.1 & 3.7 & 79.9 & & 26.6 & \\
65 & & 5.9 & 18.6 & 37.4 & 10.6 & 47.5 & & \\
55 & 11.7 & & 57.7 & & 96.5 & & 11.9 & \\
\hline
\end{tabular}


fact, metastable processes that involve the losses of $\mathrm{C}_{2} \mathrm{H}_{2} \mathrm{~N}$ and $\mathrm{C}_{3} \mathrm{HN}$ are present in high abundance only in the case of isoxazole derivatives. On the other hand, for compounds $\mathbf{2} \mathbf{a}-\mathbf{d}$ the most favored process is the loss of a hydrogen radical, except for $2 a$, for which the metastable decomposition that involves the loss of HCN is the most favored. Furthermore, only in the MIKE spectra of the oxazole derivatives, a loss of 26 mass units, attributed to the loss of acetylene, which yields a peak at $m / z 80$, is observed. Isomers $2 \mathbf{a}, \mathbf{2 b}$, and $2 c$ yield a further peak at $m / \approx 65$ produced by the loss of $\mathrm{CH}_{3} \mathrm{CN}$ (Figure 3 ).

The MIKE spectrum of the $[\mathrm{M}-\mathrm{CO}]^{1}$ ion from $1 \mathrm{e}$ $(\mathrm{m} / \mathrm{z} 109)$ shows two concomitant fragmentation processes that produce losses of DCN $(81 \mathrm{u}, 100 \%)$ and HCN (82 u, 41.3c). This fragmentation could be explained by assuming that after the loss of $\mathrm{CO}$, and the consequent opening of the fusion between the two heterocycles, there is a distribution of the deuterium atoms on the system. Thus, the loss of HCN could be attributable to atoms that come from the pyridine moiety, whereas the loss of DCN should involve atoms that belong to the oxazole; the latter process is the prevailing one. The MIKE spectrum also shows a metastable peak at $m / \approx 69(52.4 \%)$ attributable to the loss of $\mathrm{C}_{2} \mathrm{H}_{2} \mathrm{~N}$.

The different behavior of isoxazole $1 \mathbf{a}-\mathbf{d}$ and oxazole $2 \mathrm{a}-\mathrm{d}$ isomers confirms that not only the molecular ions, but the fragment ions $[\mathrm{M}-\mathrm{CO}]{ }^{\circ}$ formed in the source also have different structures. From these data it is evident that the connection of the atoms in the five-membered ring also play's an important role to drive the fragmentation of the $[\mathrm{M}-\mathrm{CO}]^{*}$ ion.

$\left[\mathrm{M}-\mathrm{CH}_{3} \mathrm{CN}\right]^{+\cdot}$ fragment ion. MIKES data of the fragment ions $\left[\mathrm{M}-\mathrm{CH}_{3} \mathrm{CN}\right]$ are reported in Table 3. The spectra of compounds $1 \mathbf{a}$ and $\mathbf{1 b}$ are shown in Figure 4. After the loss of $\mathrm{CH}_{3} \mathrm{CN}$, the structures of the corresponding isoxazole and oxazole derivatives became identical and their metastable spectra are superimposable. In all the cases, the most abundant process is the loss of $\mathrm{CO}$. As shown in Figure 4, the composite shape of the metastable peak at $m / z 65$ indicates that the reaction takes place by two competitive mechanisms with kinetic energy releases that differ by roughly 1 order of magnitude. For compounds 1 a and 2a the kinetic energy releases associated with the two processes are $T_{0,5\}}=400$ and $T_{0,5}=30 \mathrm{meV}$, respectively. It is noteworthy that $400 \mathrm{meV}$ is close to the

Table 3. MIKE spectra (relative intensity, \%) of $\left[\mathrm{M}-\mathrm{CH}_{3} \mathrm{CN}\right] \cdot(\mathrm{m} /=93)$ produced from isomers 1 and 2

\begin{tabular}{ccccc}
\hline $\operatorname{lon}$ & $\mathbf{1 a}, \mathbf{2 a}$ & $\mathbf{1 b}, \mathbf{2 b}$ & $\mathbf{1 c}, \mathbf{2 c}$ & $\mathbf{1 d}, \mathbf{2 d}$ \\
\hline \hline 67 & & 11.3 & & \\
66 & 5.2 & 32.6 & 25.7 & 68.7 \\
65 & 100 & 100 & 100 & 100 \\
42 & 12.4 & 46.4 & 58.7 & 10.4 \\
\hline
\end{tabular}
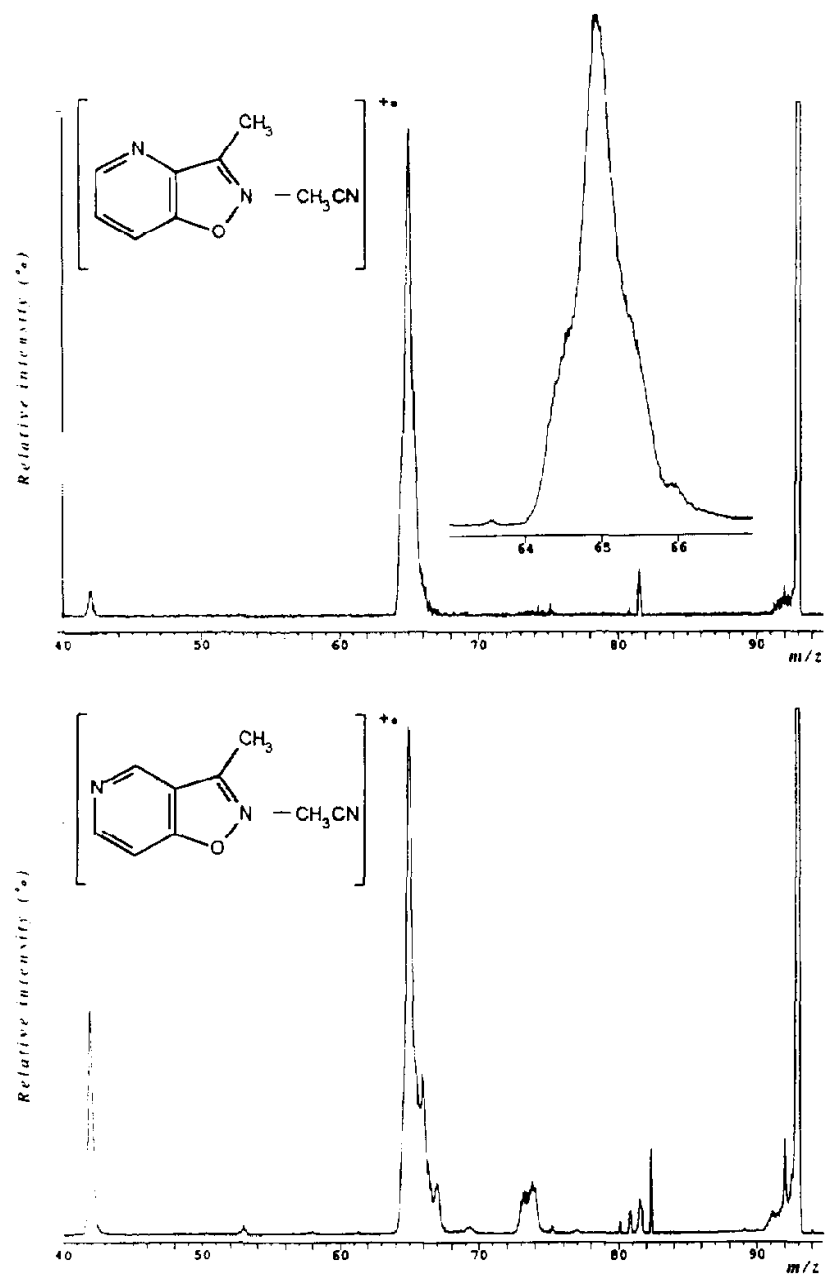

Figure 4. MIKE spectra of the $\left[\mathrm{M}-\mathrm{CH}_{3} \mathrm{CN}\right]^{+}$ion $(m / z$ 93) from isomers 1a (top) and $1 \mathrm{~b}$ (bottom). The composite shape of the peak at $m / 265$ observed in compound $1 \mathrm{a}$ is reported in the inset.

value observed for $\mathrm{CO}$ loss from the molecular ions. On the other hand, the value of $30 \mathrm{meV}$ can be attributed to reactions that involve simple bond cleavages [2]. Other metastable processes that involve the losses of $\mathrm{HCN}, \mathrm{C}_{2} \mathrm{H}_{2}$, and $\mathrm{C}_{3} \mathrm{HN}$ are also observed for isomers $b, c$, and $d$.

As regards the possible structures of the [M $\left.\mathrm{CH}_{3} \mathrm{CN}\right]^{+\cdot}$ ions, closed-ring ( $\mathbf{3 a}-\mathbf{d}, \mathbf{4 a}-\mathbf{b}$, Scheme II) and open structures, such as 5-12 (Scheme III), may be hypothesized. The MIKE data suggest exclusion of the formation of the structures $\mathbf{4 a - b}$. In fact, $4 \mathbf{a}$ might be produced equally by each of the four isomers $1 \mathbf{1 a}, \mathbf{1 d}$, $\mathbf{2 a}$, and $\mathbf{2 d}$, and similarly $\mathbf{4 b}$ by the isomers $\mathbf{1 b}, \mathbf{1 c}, \mathbf{2 b}$, and $2 c$. As a consequence, only two different MIKE spectra would be expected. However, as shown in Table 3, this does not occur because four different spectra are obtained, dependent on the position of the pyridinic nitrogen in the neutrals. This makes it likely that structures $\mathbf{4 a}$ and $\mathbf{4 b}$ do not contribute to the $\left[\mathrm{M}-\mathrm{CH}_{3} \mathrm{CN}{ }^{*}\right.$ ions. 


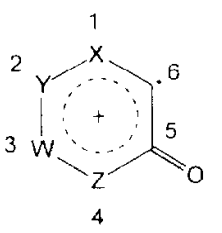

3

$$
\begin{array}{lll}
\text { a. } & X=N & Y=W=Z=C H \\
\text { b. } & Y=N & X=W=Z=C H \\
\text { c. } & W=N & X=Y=Z=C H \\
\text { d. } & Z=N & X=Y=W=C H \\
& \text { Scheme II. }
\end{array}
$$

\section{Calculations}

Neutral molecules and molcular ints. The calculated heats of formation of neutral isoxazole $1 \mathrm{a} \cdot \mathbf{d}$ and their corresponding molecular ions are reported in Table 4. As shown, the neutral molecules have quite similar stability; their calculated heats of formation fall within a $1.6-\mathrm{kcal} / \mathrm{mol}$ range. Adiabatic ionization causes an increase of heats of formation of about $210 \mathrm{kcal} / \mathrm{mol}$ and the stability of the molecular ions decreases in the order $1 c>1 b>1 d>1 a$.

Bond order (b.o.) values are reported in Table 5. Although they are "static" parameters and cannot be regarded as reactivity indices, they reflect the actual multiplicity and the covalent character of a given chemical bond [20]. In particular, a comparison of their values in the neutral molecule and in the molecular ion makes it possible to evaluate variations in bond strength that occur as a consequence of the ionization process. Their relative changes, referred to the neutral molecule and calculated according to the formula

$$
\begin{aligned}
\Delta \%= & \left\{\left[(\text { b.o. })^{\text {molecular ium }}-(\text { b.o. })^{\text {metitral }}\right] /(\text { b.o. })^{\text {lecutral }}\right\} \\
& \times 100
\end{aligned}
$$

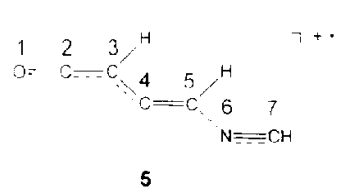

5
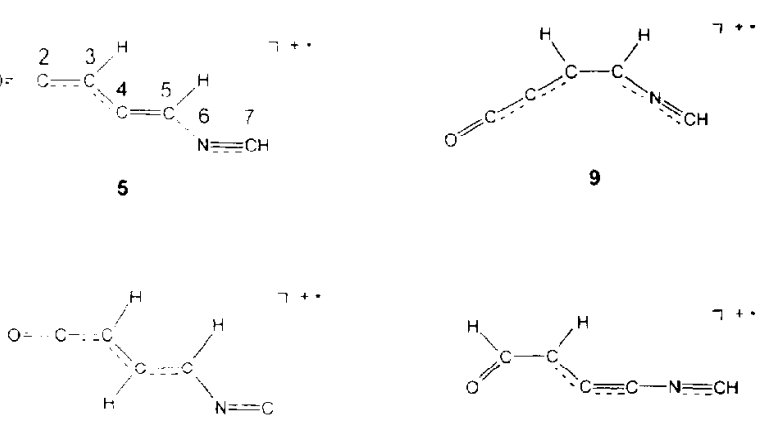

6
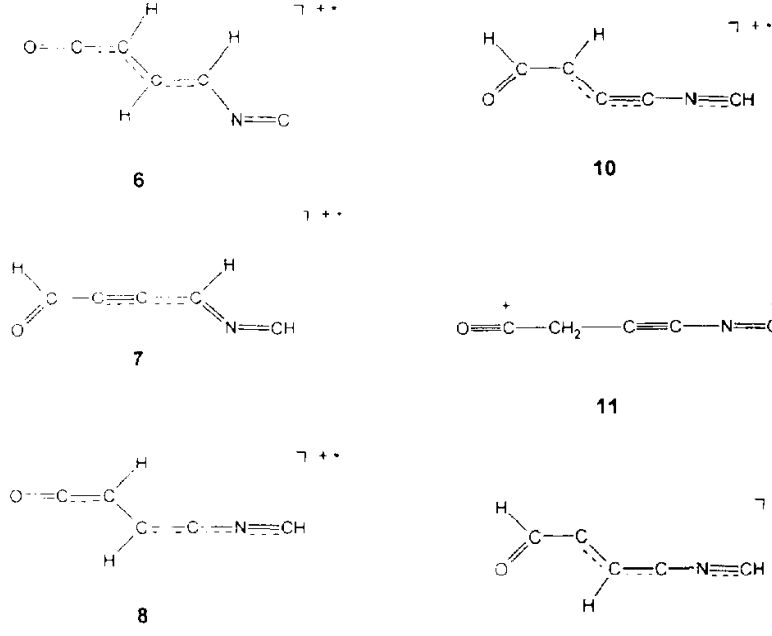

10

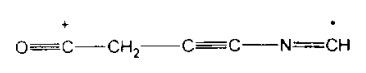

11

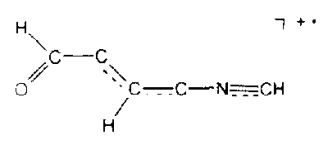

12

\begin{tabular}{|c|c|c|c|c|c|c|c|c|c|c|c|c|}
\hline \multirow[b]{2}{*}{ Bond } & \multicolumn{3}{|c|}{$1 a$} & \multicolumn{3}{|c|}{$1 \mathrm{~b}$} & \multicolumn{3}{|c|}{$1 \mathrm{c}$} & \multicolumn{3}{|c|}{$1 d$} \\
\hline & Neutral & $M$ & $\Delta \%$ & Neutral & $M^{\cdots}$ & $\Delta \%$ & Neutral & $\mathrm{M}^{+\cdot}$ & $\Delta \%$ & Neutral & $\mathrm{M}^{+\cdot}$ & $\Delta \%$ \\
\hline $\mathrm{O}(1)-\mathrm{N}(2)$ & 1.08 & 0.99 & $8 . \overline{33}$ & 1.08 & 1.21 & 12.04 & 1.09 & 1.07 & -1.83 & 1.08 & 1.00 & -7.41 \\
\hline$N(2)-C(3)$ & 1.62 & 1.80 & 11.11 & 1.72 & 1.29 & 25.00 & 1.72 & 1.64 & -4.65 & 1.72 & 1.67 & -2.91 \\
\hline$C(3\}-C(3 a)$ & 1.06 & 0.97 & -8.49 & 1.08 & 1.32 & 22.22 & 1.08 & 1.06 & -1.85 & 1.08 & 1.05 & -2.78 \\
\hline$c(3 a)-(4)$ & 1.33 & 1.56 & 17.29 & 1.28 & 1.14 & 10.94 & 1.32 & 1.46 & 10.61 & 1.31 & 1.39 & 6.11 \\
\hline$(4)-(5)$ & 1.51 & 1.26 & 16.56 & 1.49 & 1.40 & 6.04 & 1.45 & 1.07 & -26.21 & 1.49 & 1.28 & 14.09 \\
\hline$(5)-(6)$ & 1.28 & 1.17 & .8 .59 & 1.34 & 1.46 & 8.95 & 1.35 & 1.45 & 7.41 & 1.30 & 1.03 & -20.77 \\
\hline$(6)-(7)$ & 1.51 & 1.56 & 3.31 & 1.45 & 1.11 & 23.45 & 1.51 & 1.41 & -6.62 & 1.49 & 1.61 & 8.05 \\
\hline$(7)-c(7 a)$ & 1.29 & 1.12 & 13.18 & 1.30 & 1.43 & 10.00 & 1.25 & 1.08 & -13.60 & 1.32 & 1.21 & -8.33 \\
\hline$C(7 a)-O(1)$ & 1.07 & 1.34 & 25.23 & 1.10 & 1.05 & 4.55 & 1.07 & 1.26 & 17.76 & 1.09 & 1.31 & 20.18 \\
\hline$c(7 a)-c(3 a)$ & 1.31 & 1.00 & 23.66 & 1.32 & 1.15 & -12.88 & 1.34 & 1.18 & -11.94 & 1.28 & 0.99 & -22.66 \\
\hline $\mathrm{C}(3)-\mathrm{CH}_{3}$ & 0.97 & 0.95 & 2.06 & 0.97 & 0.97 & 0.00 & 0.97 & 0.96 & -1.03 & 0.97 & 0.95 & -2.06 \\
\hline
\end{tabular}

Scheme III.

Table 4. Calculated heats of formation $\left(\Delta \mathrm{H}_{\mathrm{f}}\right)$ of neutral 3-methylisoxazoles $1 \mathbf{a}-\mathbf{d}$ and their corresponding molecular ions

\begin{tabular}{ccc}
\hline & \multicolumn{2}{c}{$\begin{array}{c}\Delta H_{f} \\
\text { (kcal/mol) }\end{array}$} \\
\cline { 2 - 3 } Compound & Neutral & $\mathbf{M}^{+\cdot}$ \\
\hline \hline 1a & 31.76 & 245.14 \\
1b & 30.24 & 240.53 \\
1c & 31.84 & 240.09 \\
1d & 30.77 & 243.61 \\
\hline
\end{tabular}

Table 5. Bond order values and their relative changes ( $د$ s) for compounds 1 a $d$

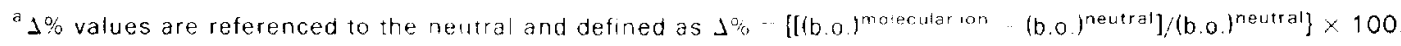


are reported in Table 5. Thus, bond weakening and strengthening that occur owing to the ionization process are indicated by negative and positive values, respectively. To evaluate the results, it is also important to consider the absolute value of the bond order, that is, bond orders significantly higher than 1.0) are not likely to dissociate, even if they are weaker in the ion than in the neutral. In cyclic molecules it is also important to consider that two bonds must be broken to observe fragmentation.

The neutral molecules 1a-d show similar bond orders. The largest difference is relevant to the $\mathrm{N}(2)-\mathrm{C}(3)$ bond for which the double bond character is more pronounced in isomers $\mathbf{1 b}-\mathbf{d}$ (b.o. 1.72) in comparison with 1a (b.o. 1.62).

After the adiabatic ionization process, a general trend is the weakening of the fusion between the two rings, which results from the decrease in the $\mathrm{C}(3 \mathrm{a})-\mathrm{C}(7 \mathrm{a})$ bond order, whose values average 1.31 in the neutral molecules and 1.08 in the molecular ions. 1a shows a remarkable increment of the $\mathrm{N}(2)-\mathrm{C}(3)$ bond order from 1.62 to 1.80 , as well as the weakening of the $\mathrm{O}(1)-\mathrm{N}(2)$ and $\mathrm{C}(3)-\mathrm{C}(3 \mathrm{a})$ bonds, whose bond orders became less than 1 , in agreement with the prevailing loss of $\mathrm{CH}_{3} \mathrm{CN}$. Furthermore, the adiabatic ionization causes a significant strengthening of the $\mathrm{C}(7 \mathrm{a})-\mathrm{O}(1)$ bond order for isomers $1 \mathrm{a}, \mathbf{1 c}$, and $\mathbf{1 d}$, in accordance with a loss of $\mathrm{CO}$ from the molecular ion.

From the examination of the data reported in Table 5 , it appears that $\mathbf{1 b}$ shows bchavior different from the other isomers. This behavior may be related to differences also observed in the electronic spectra, in which the composite band at $280 \mathrm{~nm}$, observed in the $\mathrm{LV}$ spectra of 1a, 1c, and 1d [26], is completely absent in the case of $\mathbf{1 b}$.

$\left[\mathrm{M}-\mathrm{CH}_{3} \mathrm{CN}^{+\cdot}\right.$ fragment ion. Molecular orbital calculations also have been carried out on both open- and closed-ring $\left[\mathrm{M}-\mathrm{CH}_{3} \mathrm{CN}\right]^{1}$ tragment ions. Heats of formation and bond orders for closed-ring species (3a-d, 4a-b; Scheme 11 ) are reported in Tables 6 and 7 . respectively.

The pyridone radical cations ( $\mathbf{3 a}-\mathbf{d})$ show small (4) $-C(5)$ and $C(5)-C(6)$ bond orders, which suggests the opening of the ring and the elimination of $\mathrm{CO}$, observed both in EI [17] and in MIKE spectra (Table 3). On the other hand, the bond order values found in these structures do not allow us to explain
Table 6. Calculated heats of formation $\left(\Delta H_{f}\right)$ for $\left[\mathrm{M}-\mathrm{CH}, \mathrm{CN}^{*}{ }^{*}\right.$ fragment ions

\begin{tabular}{lcc} 
Compound & $\begin{array}{c}\Delta H_{f} \\
\{\mathrm{kcal} / \mathrm{mol}\}\end{array}$ & $\begin{array}{c}\Delta H_{\mathrm{f}} \\
\text { relative to 3a }\end{array}$ \\
\hline \hline Ring forms & & \\
3a & 279.82 & 0 \\
$\mathbf{3 b}$ & 302.57 & \\
$\mathbf{3 c}$ & 286.76 & \\
$\mathbf{3 d}$ & 298.68 & \\
$\mathbf{4 a} \equiv \mathbf{4 d}$ & 325.52 & \\
$\mathbf{4 b} \equiv \mathbf{4 c}$ & 321.25 & \\
& & \\
Open forms & & -24.49 \\
$\mathbf{5}$ & & -21.90 \\
$\mathbf{6}$ & 255.33 & -20.60 \\
$\mathbf{7}$ & 257.92 & -14.03 \\
$\mathbf{8}$ & 259.22 & -13.17 \\
$\mathbf{9}$ & 265.79 & -7.37 \\
$\mathbf{1 0}$ & 266.65 & -0.60 \\
$\mathbf{1 1}$ & 272.45 & 39.89 \\
$\mathbf{1 2}$ & 279.22 & \\
\hline & 319.71 & \\
\hline
\end{tabular}

Table 7. Bond orders for closed-ring $\left[\mathrm{M}-\mathrm{CH}_{3} \mathrm{CN}\right]^{+}$. fragment ions

\begin{tabular}{lcccccc}
\hline Bond & 3a & 3b & 3c & 3d & $\mathbf{4 a ~} \equiv \mathbf{4 d}$ & $\mathbf{4 b} \equiv \mathbf{c}$ \\
\hline \hline$(1)-(2)$ & 1.00 & 1.03 & 1.11 & 1.23 & 1.28 & 1.41 \\
$(2)-(3)$ & 1.30 & 1.61 & 1.34 & 1.08 & 1.24 & 1.39 \\
$(3)-(4)$ & 1.58 & 1.22 & 1.59 & 1.75 & 1.34 & 1.14 \\
$(4)-C(5)$ & 0.92 & 0.93 & 0.85 & 0.83 & 1.43 & 1.65 \\
$C(5)-O$ & 2.36 & 1.95 & 1.94 & 2.02 & 1.07 & 1.01 \\
$O-C(6)$ & & & & & 1.08 & 1.16 \\
$C(5)-C(6)$ & 0.77 & 0.93 & 0.98 & 0.94 & 1.02 & 1.04 \\
$C(6)-1$ & 2.24 & 1.77 & 1.69 & 1.65 & 1.54 & 1.21 \\
\hline
\end{tabular}

the elimination of $\mathrm{HCN}$ and $\mathrm{C}_{3} \mathrm{HN}$ found in the MIKE spectra (Table 3 ).

Other closed-ring structures that have the oxygen atom bridging $C(5)$ and $C(6)$ also have been studied $(4 a, b)$. All their bond orders are higher than 1, which does not allow prediction of which fragmentations will occur. Furthermore structures $4 \mathrm{a}$ and $\mathbf{4 b}$ are less stable than their corresponding pyridone isomers $\mathbf{3 a}-\mathbf{d}$ (Table 6). These results are in good agreement with the con-

Table 8. Bond orders for open-ring $\left[\mathrm{M}-\mathrm{CH}_{i} \mathrm{CN}\right]^{\text {" ions }}$

\begin{tabular}{lcccccccc}
\hline Bond & $\mathbf{5}$ & $\mathbf{6}$ & $\mathbf{7}$ & $\mathbf{8}$ & $\mathbf{9}$ & $\mathbf{1 0}$ & $\mathbf{1 1}$ & $\mathbf{1 2}$ \\
\hline \hline $\mathrm{O}(1)-\mathrm{C}(2)$ & 223 & 2.36 & 2.00 & 2.28 & 2.14 & 1.96 & 2.58 & 1.91 \\
$\mathrm{C}(2)-\mathrm{C}(3)$ & 129 & 1.22 & 0.91 & 1.39 & 1.62 & 0.93 & 0.85 & 1.00 \\
$\mathrm{C}(3)-\mathrm{C}(4)$ & 139 & 1.36 & 2.60 & 1.16 & 1.89 & 1.38 & 1.02 & 1.69 \\
$\mathrm{C}(4)-\mathrm{C}(5)$ & 199 & 1.32 & 1.22 & 1.61 & 0.95 & 2.34 & 2.64 & 1.20 \\
$\mathrm{C}(5)-\mathrm{N}(6)$ & 076 & 1.13 & 1.02 & 1.40 & 1.11 & 1.15 & 1.08 & 1.00 \\
$\mathrm{~N}(6)-\mathrm{C}(7)$ & 2.70 & 2.10 & 2.50 & 2.23 & 2.41 & 2.48 & 1.94 & 2.49 \\
\hline
\end{tabular}


clusions drawn on the basis of only the MIKE data and again indicate that the radical cations $4 \mathbf{a}, \mathbf{b}$ may be excluded as possible structures for the $[\mathrm{M}$ $\left.\mathrm{CH}_{3} \mathrm{CN}\right]^{+\cdot}$ fragment ions produced by $\mathbf{1 a}-\mathbf{d}$ or $\mathbf{2 a}-\mathbf{d}$.

In addition to closed-ring structures, calculations also were extended to a set of open forms produced by breaking the $C(5)-C(6)$ bond in compound 3a (5-12, Scheme III). The open structures 5-11 have a lower heat of formation than that of their parent structure 3a (Table 6), which suggests that they can be formed easily owing to electron ionization. Furthermore their heats of formation fall in a narrow range of energy $(0-25 \mathrm{kcal} / \mathrm{mol})$ with respect to $3 \mathbf{a}$, which indicates that each of these structures might be formed in the fragmentation process and that a mixture of these isomeric forms may exist in the gas phase. From examination of the bond orders of the open forms $5-12$ (Table 8), it appears that structure 5, which is also the most stable, has the smallest $\mathrm{C}(5)-\mathrm{N}(6)$ bond order (equal to 0.76), which suggests the elimination of HCN. Through a 1,3 hydrogen rearrangement, 5 might give rise to the distonic ion 11, which shows bond order values in agreement with losses of both $\mathrm{CO}$ and $\mathrm{C}_{3} \mathrm{HN}$ evidenced by MIKE spectra (Table 3 ). Therefore it is possible that both open structures and closed-ring species contribute to the ion $\left[\mathrm{M}-\mathrm{CH}_{3} \mathrm{CN}\right]^{+ \text {. }}$.

On the basis of the experimental data and calculations, a fragmentation mechanism is proposed for compound 1a (Scheme IV). It is likely that the loss of $\mathrm{CH}_{3} \mathrm{CN}$ from the molecular ion yields both the cyclic structure 3a, which may easily lose $\mathrm{CO}$, and the open structure 5. The latter may fragment by loss of $\mathrm{HCN}$ or, through a hydrogen transposition, produce the open structure 11, whose bond orders indicate the possible elimination of both $\mathrm{CO}$ and $\mathrm{C}, \mathrm{HN}$. It follows that two different reactions would yield the loss of $\mathrm{CO}$ from structures 3a and 11. This is in agreement with the composite peak shape of the $\left[\left(\mathrm{M}-\mathrm{CH}_{3} \mathrm{CN}\right)-\mathrm{CO}\right]^{+}$. ion observed in the MIKE spectrum (Figure 4).

\section{Correlation With Photochemistry}

In previous photochemical studies a correlation between the phenomena observed when a molecule was photoirradiated and those caused by electron ionization was found [14]. In particular, it is well known that the photochemical rearrangements of isoxazolopyridines to the corresponding oxazole derivatives is a quite general process [27].

On the other hand, the present tandem mass spectrometry investigation has shown that the behavior under electron ionization of the isoxazoles examined is deeply different from that observed in photochemical reactions. It follows that correlations between the two methodologies are not found in the present case.

\section{Conclusions}

From the present study, it is evident that MIKE spectrometry is a useful analytical tool for the characterization and differentiation of 3-methylisoxazolo- and 2methyloxazolopyridine isomers. The molecular ions from isoxazole $\mathbf{1 a}-\mathbf{d}$ and oxazole $\mathbf{2} \mathbf{a}-\mathbf{d}$ derivatives give quite different MIKE spectra that indicate that each compound keeps a characteristic structure after electron ionization. The data show that the position of the nitrogen atom in the pyridine ring also has a significant effect on the fragmentation.

The MIKE spectra of $[\mathrm{M}-\mathrm{CO}]^{-\cdot}$ fragment ions also show large differences among the isomers. These indicate that the isomers remain distinct even in some fragment ions produced in the source region. The loss

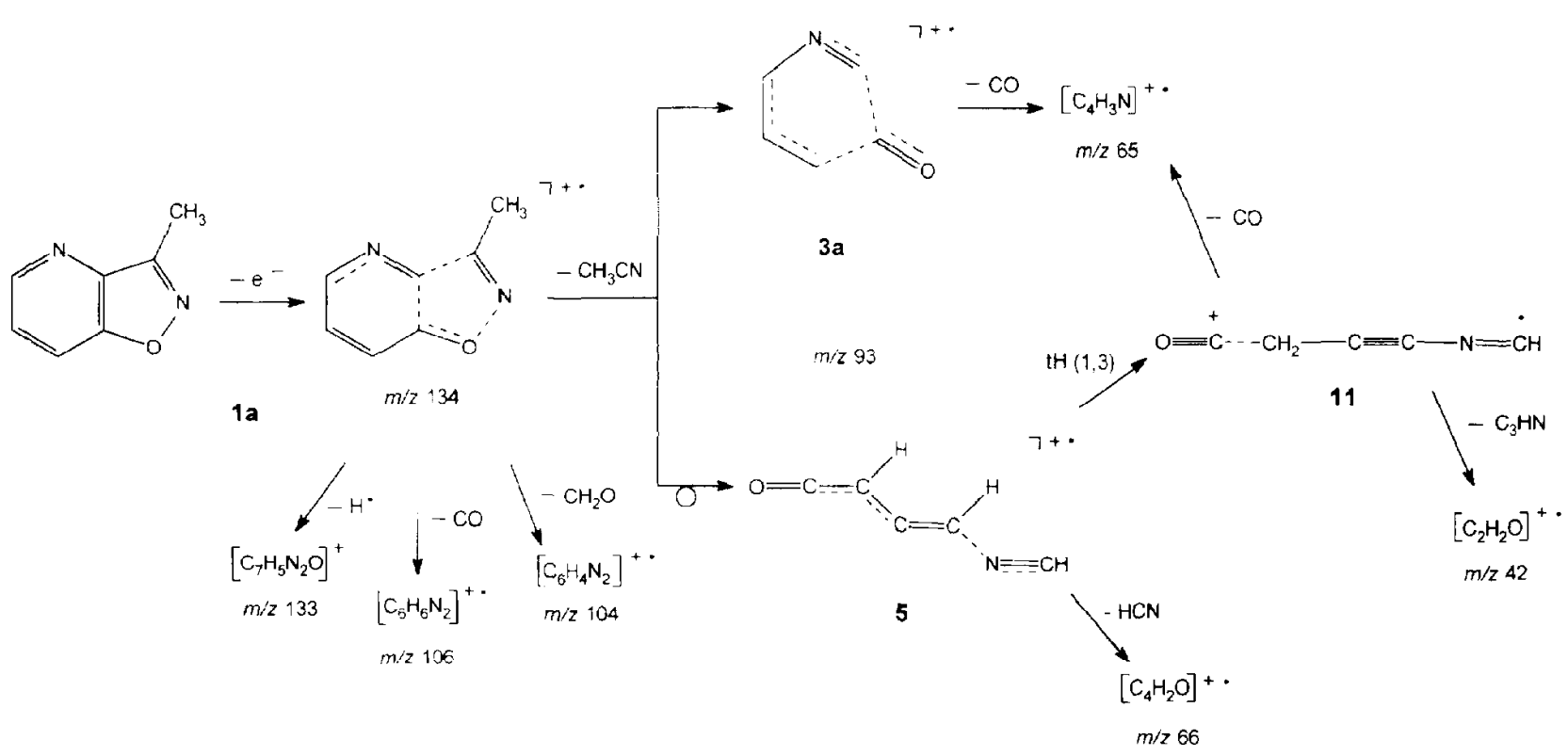

Scheme IV. 
of $\mathrm{CH}_{3} \mathrm{CN}$ removes the distinction between corresponding 3-methylisoxazolo- (1a-d) and 2-methyloxazolopyridines $(2 \mathbf{a}-\mathbf{d})$, but it is still possible to distinguish the fragment ions derived from neutrals that differ in the position of the pyridinic nitrogen.

This behavior is significantly different from that observed in analogous heterocyclic systems. In particular, the isomerization of the isoxazole moiety to oxazole was not observed in the heterocyclic systems examined in this study.

Calculations carried out on both neutrals as well as on molecular and fragment ions of compounds $1 a-d$, have suggested a qualitative approach in the elucidation of the fragmentation pathways.

\section{Acknowledgments}

G.G. wishes to thank the Commission of the European Community for a fellowship (ERB-CIPA-CT-92-1506) in the ambit of Community's Action for Cooperation in Science and Technology with Central and Eastern European Countries.

\section{References}

1. Bush, K. L.; Glish, G. L.; McLuckey, S. A. In Mass Spectromitry / Mass Spectrometry: Teininizes and Applications of Tandem Mass Spectrometry; VCH: New York, 1988.

2. Cooks, R. G.; Beynon, J. H.; Caprioli, R. M.; Lester G. R. In Metastable Ions; Elsevier Scientific Amsterdam, 1973.

3. Porter, Q. N. In Mass Spectromitry of Heterocudic Compulmits, 2nd ed.; Wiley: Now York, 1985; pp 848-892 and references therein.

4. De Jongh, D. C.; Thomson, M. I. 1. Org. Chem. 1973, 38, $1356-1361$.

5. Maquiestau, A.; Van Haverbeke, Y.; Flammang, R.; Pierard, I. Bull. Soc. Chim. Bits. 1975, 84, 20; 211.

6. Reichen, W. Helu. (him. Acta 1977, bol. 186 190).

7. Tsiamis, C.; Tsoungas, P. C. 1. Heterocytic Chem. 1985, 22. $687-691$
8. Dyall, L. K.; Karpa, G. J. Org. Mass Spectrom. 1989, 24, 70-73.

9. Guarna, A.; Moneti, G. Org. Mass Spectrom. 1989, 24, 490-496.

10. Cojocaru, M.; Hassner, A.; Maurya, R. Org. Mass Spectrom. 1991, 26, 667-668

11. Flammany, R.; Plisnier, M.; Bouchoux, G.; Hoppilliard, Y.; Humbert, S.; Wentrup, C. Org. Mass Spectrom. 1992, 27, $317-325$.

12. Favretto, D.; Traldi, P.; Bravo, P.; Diliddo, D.; Resnati, G. Rapit Conm. Mass Spectrom. 1993, 7, 665-669.

13. Lllman, E. F.; Singh, B. J. Am. Chem. Soc. 1966, 88, 1844-1845.

14. Nakata, H.; Sakurai, H.; Yoshizumi, H.; Tatematsu, A. Org. Mass Spectrom. 1968, 1, 199-204.

15. Maquestiau, A.; Van Haverbeke, Y.; De Meyer, C.; Flammang, R. Org. Mass Spectrom. 1974, 9, 149-151.

16. Selva, A.; Vettori, U.; Gaetani, E. Org. Mass Spectrom. 1974, 9. 1161-1165.

17. Ponticelli, F.; Giomi, D.; Papaleo, S.; Tedeschi, P. Org. Mass Spectrom. 1993, 28, 451-454.

18. Radom, L. Org. Mass Spectrom. 1991, 26, 359-373.

19. Somogyi, Á.; Gömöry, Á.; Vékey, K.; Tamás, J. Org. Mass Spectron. 1991, 26.936-938.

20. (a) Somogyi, Á.; Wysocki, V. H.; Mayer, I. J. Am. Soc. Mass Spectrom. 1994, 5. 704-717; (b) McCormack, A. L.; Somogyi, A.; Dongré, A. R.; Wysocki, V. H. Anal. Chem. 1993, $2859-2872$.

21. Dewar, M. J. S.; Thiel, W. I. Am. Chen. Soc. 1977, 99, $4899-4906$.

22. Finch, N.; Robison, M. M.; Valerio, M. P. J. Org. Chem. 1972, $37,51-54$

23. Chimichi S.; Nesi, R.; Ponticelli, F.; Tedeschi P. Magn. Res. (

24. Stewart, J. P. F. J. Seiler Research Laboratory, US Air Force Academy, Colorado Springs, 1987

25. Holmes, J. L.; Terlouw, J. K. Org. Mass Spectrom. 1980, 15 , $383 \cdot 396$

26. Chimichi, S.; Tedeschi, P.; Camparini, A.; Ponticelli, F. Org. Magn. Res. 1982, 20, 141-144 and references therein.

27. Donati, D.; Fusi, S.; Ponticelli, F. Heterocycles 1988, 27, $1899-1905$. 